Canadian

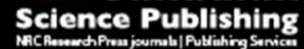

Canadian Journal of Chemistry Revue canadienne de chimie

\title{
An Affinity-based Probe for Methyltransferase Enzymes Based on Sinefungin
}

\begin{tabular}{|c|c|}
\hline Journal: & Canadian Journal of Chemistry \\
\hline Manuscript ID & cjc-2017-0168.R1 \\
\hline Manuscript Type: & Article \\
\hline Date Submitted by the Author: & 14-Jun-2017 \\
\hline Complete List of Authors: & $\begin{array}{l}\text { Lafreniere, Matthew; University of Ottawa, Chemistry and Biomolecular } \\
\text { Sciences } \\
\text { Desrochers, Genevieve ; University of Ottawa, Chemistry and Biomolecular } \\
\text { Sciences } \\
\text { Mekbib, Kedous; University of Ottawa, Chemistry and Biomolecular } \\
\text { Sciences } \\
\text { Pezacki, John; University of Ottawa, Chemistry and Biomolecular Sciences }\end{array}$ \\
\hline $\begin{array}{r}\text { Is the invited manuscript for } \\
\text { consideration in a Special } \\
\text { Issue?: }\end{array}$ & N/A \\
\hline Keyword: & $\begin{array}{l}\text { Activity-based protein profiling, sinefungin, enzyme activity, } \\
\text { methyltransferases, epigenetics }\end{array}$ \\
\hline
\end{tabular}

\section{SCHOLARONE"}

Manuscripts 


\section{An Affinity-based Probe for Methyltransferase Enzymes Based on Sinefungin}

Matthew A. Lafreniere ${ }^{1}$, Genevieve F. Desrochers ${ }^{1}$, Kedous Mekbib ${ }^{1}$, and John Paul Pezacki ${ }^{1,2^{*}}$

1. Department of Chemistry and Biomolecular Sciences, University of Ottawa, 10 Marie Curie Street, Ottawa, ON, Canada, K1N 6N5

2. Department of Biochemistry, Microbiology, and Immunology, University of Ottawa, 451 Smyth Road, Ottawa, ON, Canada, K1H 8M5

* Corresponding author: john.pezacki@uottawa.ca 
Epigenetics controls numerous cellular processes, such as gene transcription, signal transduction, and protein stabilization. An understanding of epigenetic mechanisms can lead to the development of therapeutic agents for various diseases. Herein, we report the design and synthesize a sinefungin activity-probe (BpyneSF) that targets methyltranferase enzymes and proteins involved in recognition of methylation. This probe contains a bioorthogonal alkyne residue for conjugation using the copper catalyzed azide-alkyne cycloaddition and a photoactivatable crosslinker group for covalent attachment of the probe to its proteomic targets. We investigate the efficiency and selectivity of the probe to inhibit and label methyltransferase enzymes and we demonstrate, through in-gel fluorescence, on-bead digestion and tandem mass spectrometry, that BpyneSF can label methyltransferase SETD2 and reader proteins in vitro. These results establish the utility of BpyneSF as a tool for activity-based protein profiling in complex biological environments.

Keywords

Affinity-based protein profiling, Sinefungin, enzyme activity, methyltransferases, epigenetics 
Epigenetics refers to changes in heritable phenotypic traits caused by alterations in gene expression rather than in the genetic code. Control of phenotype expression involves the diverse interaction between regulator RNAs, DNA methylation, and histone modification ${ }^{1}$. Disruption of one of these essential epigenetic regulators can result in epigenetic diseases, such as congenital disorders, cancers, and neurodegenerative diseases ${ }^{2,3}$. Importantly, methylation of DNA and proteins regulate numerous biological processes, such as gene transcription, signal transduction, and protein stabilization ${ }^{3,4}$. Given the importance of methylation to normal physiological function and its contribution to human disease, DNA and protein methyltransferases have emerged as important group of enzymes targeted for development of novel pharmacological agents $^{5-7}$. In reactions catalyzed by methyltransferases, cofactor $S$-(5'-Adenosyl)- $L$-methionine (SAM) (Fig.1b) is used to transfer a methyl group to biological substrates, such as CpG islands in DNA or histone tails in nucleosomes ${ }^{2,8,9}$. Analogues of SAM and $S$-(5'-Adenosyl)- $L$ homocysteine (SAH), a selective feedback inhibitor that results from methyl transfer, have been developed as versatile tools to study SAM-dependent methyltransferases ${ }^{10}$.

Sinefungin (Fig.1b) was originally isolated from Streptomyces sp. K05-0178 and tested as a novel antibiotic for Trypanosoma brucei, the parasitic source for human African trypanosomiasis or sleeping sickness ${ }^{11}$. Sinefungin (SF) is a nucleoside analogue of SAH and has been used as a scaffold to design selective inhibitors for protein lysine methyltransferases ${ }^{12-14}$. Previous reports have used sinefungin to investigate the mechanism by which SET domain methyltransferases catalyze the transfer of methyl groups to protein biomolecules ${ }^{13}$. A major drawback of sinefungin is that it is a non-selective, reversible, pan-inhibitor of methyltransferases and lacks potency against a panel of protein methyltransferases ${ }^{5}$. However, the lack of sinefungin selectivity is advantageous as it permits the study of a broad variety of 
methyltransferases in parallel. In this study, we develop a photoactive chemical probe based on the reversible inhibitor sinefungin (Fig.1a) and undertake preliminary investigation into its effectiveness as an affinity probe for methyltransferases.

Chemoproteomics methods aim to provide insight on the mode of actions of small molecule chemical probes and to characterize and assign function to proteins and enzymes in complex biological environments ${ }^{15-20}$. Through the use of affinity- and activity-based chemical probes (Fig. 2), a variety of different proteins have been studied such as proteases, phosphatases, hydrolases, and kinases ${ }^{21-23}$. To prepare our photoactive chemical probe BpyneSF (Fig.1a), we introduced the photoactive moiety benzophenone $(\mathrm{Bp})$ to the core probe structure (Fig.1a). The inclusion of Bp enables the covalent modification of target methyltransferases and associated binding proteins, previously demonstrated with other Bp-containing activity probes ${ }^{24,25}$. In addition to the Bp moiety, a biologically inert alkyne was appended to the probe to facilitate the incorporation of a reporter tag through copper (I)-catalyzed azide-alkyne cycloaddition $(\mathrm{CuAAC})^{26,27}$. Initially, sinefungin was protected with di-tert-butyl dicarbonate in water to facilitate amide coupling to the Bpyne. As shown in Figure 1a, benzophenone was first coupled to 5-hexynoic acid, followed by coupling to N-(tert-Butoxycarbonyl)glycine by HATU-mediated coupling $^{28}$. Trifluoroacetic acid was used to deprotected Bpyne-gly-BOC and Bpyne-gly- $\mathrm{NH}_{2}$ was subsequently coupled to (Boc) $)_{2}$-sinefungin. Finally, (Boc) $)_{2}$-sinefungin was deprotected in acid to yield BpyneSF. Following the synthesis, UV-induced covalent attachment of BpyneSF to target enzymes could visualized through in-gel fluorescent (Fig. 2).

To validate the effectiveness of BpyneSF (Fig. 3a) as an affinity probe, we evaluated in vitro labeling of human embryonic kidney cells (HEK293). The HEK293 cell line and its derivatives are commonly used in wide variety of experiments ranging from signal transduction 
to protein interaction studies and represent an ideal cell line for study ${ }^{29}$. The optimal labeling concentration of BpyneSF was determined by treatment of HEK293 proteome lysates with increasing probe concentrations (Fig.3b) followed by covalent attachment of rhodamine-azide via CuAAC. Levels of background labeling by BpyneSF were assessed with a sample that was not exposed to ultraviolet light (Fig.3b, no ho lane). Further optimization was undertaken to determine the ideal time for probe incubation (Fig.4a) and CuAAC attachment of rhodamine azide (Fig.4b). The labeling concentration and incubation time that showed the strongest labeling with minimal background was determined to be $10 \mu \mathrm{M}$ and 5 minutes, respectively. Following incubation, the sample was UV irradiated for 15 minutes at room temperature. The intense bands detected in the region around 100, 50, and $40 \mathrm{kDa}$ by in-gel fluorescent detection suggests that the BpyneSF probe has a greater selectivity for these proteins, in addition to other faintly visible bands along the mass gradient. Overall, these results indicate that BpynSF can selectively target proteins in the HEK293 proteome.

To elucidate the targeted subclasses of methyltransferase enzymes by BpyneSF, we undertook competitive labeling of HEK293 proteome with 1-Benzyl-3,5-bis-(3-bromo-4hydroxylbenzylidene)piperidin-4-one, a small molecule inhibitor of coactivator-associated arginine methyltransferase $(\mathrm{CARM} 1)^{30}$. CARM1 inhibitor is a cell-permeable (bisbenzylidene)piperidinone derivative that is reported to display potent and selective inhibition of CARM1/Protein arginine methyltransferase 4 (PRMT4), with low or no activity against a diverse panel of arginine and histone lysine methyltransferase enzymes ${ }^{30}$. As previously reported, CARM1 inhibitors can inhibit protein arginine N-methyltransferase 1 (PRMT1) and CARM1/PRMT4 with $\mathrm{IC}_{50}$ values of $63 \mu \mathrm{M}$ and $7.1 \mu \mathrm{M}$, respectively ${ }^{30}$. We treated freshly isolated HEK293 with $10 \mu \mathrm{M}$ and $100 \mu \mathrm{M}$ inhibitor or DMSO control, followed by incubation 
with $10 \mu \mathrm{M}$ BpyneSF, irradiation at a wavelength of $365 \mathrm{~nm}$, and $\mathrm{CuAAC}$-mediated tagging of rhodamine-azide. The reactions were then quenched with cold acetone, separated by SDS-PAGE, and rhodamine-tagged BpyneSF was detected by in-gel fluorescence scanning. Treatment with $100 \mu \mathrm{M}$ CARM1 inhibitor resulted in a concentration-dependent decrease in fluorescence signal intensity in comparison with the no inhibitor control and the $10 \mu \mathrm{M}$ CARM1 inhibitor (Fig 4c, lane 4 vs. lane 5). This decrease in signal intensity across the mass gradient of the $100 \mu \mathrm{M}$ CARM1 inhibitor lane suggests that at higher concentrations the CARM1 inhibitor can inhibit off-target enzymes and proteins, such as PRMT1 and others. PRMT1, which methylates arginine on histone $\mathrm{H} 4$ and has a molecular weight of approximately $68 \mathrm{kDa}$, has previously been shown to be targeted by sinefungin ${ }^{31}$. As observed in figure $4 c$, the decrease in signal intensity of a band at approximately $68 \mathrm{kDa}$ suggests that this protein band is PRMT1 and that it is targeted by our BpyneSF probe; however, further validation is required to confirm this. Overall, these results suggest that BpyneSF can covalently modify subclasses of methyltransferase enzymes.

To identify methyltransferase enzymes and the binding proteins that recognize methylated biological targets, we treated HEK293 lysates with $10 \mu \mathrm{M}$ BpyneSF as previously described and tagged the probe-labeled proteins with biotin-azide. Using this method, labeled proteins can be isolated by streptavidin-coated beads and digested with trypsin for subsequent LC-MS/MS analysis (Fig. 2). LC-MS/MS analysis identified histone-lysine N-methyltransferase (SETD2) as a target of BpyneSF in addition to several proteins involved in recognition of methylated biomolecules. SETD2 tri-methylates lysine position 36 (Lys26) on histone H3 (H3K36me3), which results in the recruitment of protein complexes that carry out transcription elongation, RNA processing, and DNA repair ${ }^{32,33}$. Previous research has demonstrated that sinefungin can specifically target SETD2 enzyme, however, we did not observe banding at the 
predicted molecular weight of SETD2 in our experiment ${ }^{10,12}$. The lack of fluorescent visualization of SETD2 enzyme may be due to low SETD2 abundance in HEK293 proteome or due to high foreground fluorescent intensity that may limit band visualization. To validate our LC-MS/MS results and confirm the selectivity of BpyneSF for methyltransferase enzymes, recombinant SETD2, PRMT1, and CARM1 were labelled in vitro as previously described (Fig.5). We observed fluorescent bands at the molecular weight of each recombinant methyltransferase in the presence of BpyneSF and $365 \mathrm{~nm}$ radiation, and no fluorescence in the absence of BpyneSF. Total protein imaging shows equal loading for all three methyltransferases (Fig. S2). These results suggest that BpyneSF labels methyltransferase enzymes.

In addition to targeting SETD2, BpyneSF also captured methyl methanesulfonatesensitivity protein 22 (MMS22L) and tudor domain-containing protein 6 (TDRD6). MMS22L is a histone chaperone and in complex with TONSL has been shown to bind to methylated lysine on histones $\mathrm{H} 3$ and $\mathrm{H} 4$ and regulates the replicative state of $\mathrm{DNA}^{34,35}$. Tudor domain proteins are epigenetic "readers" that directly interact with other proteins through methylated arginine or lysine residues $^{36,37}$. Both MMS22L and TDRD6 are associated with methylated lysine and arginine residues and were likely non-specifically captured by our probe. Further validation of different cellular proteomes is required to confirm that BpyneSF can non-specifically bind proteins involved in the methyl group recognition. Despite the limitations outlined above, these results suggest that BpyneSF is capable of labeling methyltransferase and binding proteins that recognize methylated biological targets.

Herein we report the design and synthesis of a sinefungin probe that can covalently modify methyltransferase enzymes using a photo-crosslinking strategy and label in an affinitydependent manner, several proteins simultaneously. Our work demonstrates that the reversible 
binding of sinefungin that transiently bind to methyltransferase enzymes can be designed to permanent modify their target enzymes, permitting identification and characterization of enzyme targets. We further demonstrated that in conjunction with small molecule inhibitors, BpyneSF can be used to deconvolute the potential targets of chemical probes and associated binding proteins. Future work will involve the further refinement of the probe design as well as the identification and characterization of target methyltransferases and interacting proteins involved in recognition of biological methylation in disease models.

\section{Experimental Section}

Synthetic methods and experimental details are described in the Supporting Information.

\section{Acknowledgements}

We thank Dr. Alison Sherratt for useful through the course of this work. J.P.P thank the Natural Sciences and Engineering Research Council of Canada (NSERC) for funding

\section{References}

1. $\quad$ Egger, G.; Liang, G.; Aparicio, A.; Jones, P. A. Nature 2004, 429, 457-63.

2. Rodenhiser, D.; Mann, M. Can. Med. Assoc. J. 2006, 174, 341-8. 
3. Dawson, Mark A.; Kouzarides, T. Cell 2012, 150, 12-27.

4. Lee, Y. H.; Stallcup, M. R. Mol Endocrinol 2009, 23, 425-33.

5. $\quad$ Copeland, R. A.; Solomon, M. E.; Richon, V. M. Nat. Rev. Drug Discov. 2009, 8, $724-$

32.

6. Ma, W. W.; Adjei, A. A. CA Cancer J Clin 2009, 59, 111-37.

7. $\quad$ Cortez, C. C.; Jones, P. A. Mutat. Res. 2008, 647, 44-51.

8. $\quad$ Fontecave, M.; Atta, M.; Mulliez, E. Trends Biochem. Sci. 2004, 29, 243-9.

9. Struck, A. W.; Thompson, M. L.; Wong, L. S.; Micklefield, J. Chembiochem 2012, 13, 2642-55.

10. Zhang, J.; Zheng, Y. G. ACS Chem Biol 2016, 11, 583-97.

11. Niitsuma, M.; Hashida, J.; Iwatsuki, M.; Mori, M.; Ishiyama, A.; Namatame, M.;

Nishihara-Tsukashima, A.; Matsumoto, A.; Takahashi, Y.; Yamada, H.; Otoguro, K.; Shiomi, K.; Omura, S. J. Antibiot. 2010, 63, 673-9.

12. Zheng, W.; Ibanez, G.; Wu, H.; Blum, G.; Zeng, H.; Dong, A.; Li, F.; Hajian, T.; AllaliHassani, A.; Amaya, M. F.; Siarheyeva, A.; Yu, W.; Brown, P. J.; Schapira, M.; Vedadi, M.;

Min, J.; Luo, M. J. Amer. Chem. Soc. 2012, 134, 18004-14.

13. Couture, J. F.; Hauk, G.; Thompson, M. J.; Blackburn, G. M.; Trievel, R. C. J. Biol. Chem. 2006, 281, 19280-7.

14. Devkota, K.; Lohse, B.; Liu, Q.; Wang, M. W.; Staerk, D.; Berthelsen, J.; Clausen, R. P. ACS Med. Chem. Lett. 2014, 5, 293-7.

15. Cravatt, B. F.; Wright, A. T.; Kozarich, J. W. Annu. Rev. Biochem. 2008, 77, 383-414.

16. Desrochers, G. F.; Sherratt, A. R.; Blais, D. R.; Nasheri, N.; Ning, Z.; Figeys, D.; Goto,

N. K.; Pezacki, J. P. ACS Infect. Dis. 2015, 1, 443-52.

17. Lafreniere, M. A.; Powdrill, M. H.; Singaravelu, R.; Pezacki, J. P. ACS Infect. Dis. 2016, 2, 863-871.

18. Nasheri, N.; Ning, Z.; Figeys, D.; Yao, S.; Goto, N. K.; Pezacki, J. P. Proteomics 2015, $15,3815-25$.

19. Sherratt, A. R.; Nasheri, N.; McKay, C. S.; O'Hara, S.; Hunt, A.; Ning, Z.; Figeys, D.; Goto, N. K.; Pezacki, J. P. ChemBioChem 2014, 15, 1253-1256.

20. Wright, M. H.; Sieber, S. A. Nat. Prod. Rep. 2016, 33, 681-708.

21. Sherratt, A. R.; Nasheri, N.; McKay, C. S.; O'Hara, S.; Hunt, A.; Ning, Z.; Figeys, D.;

Goto, N. K.; Pezacki, J. P. Chembiochem 2014, 15, 1253-6.

22. Willems, L. I.; Overkleeft, H. S.; van Kasteren, S. I. Bioconjug. Chem. 2014, 25, 1181-

91.

23. Won, S. J.; Eschweiler, J. D.; Majmudar, J. D.; Chong, F. S.; Hwang, S. Y.; Ruotolo, B. T.; Martin, B. R. ACS Med. Chem. Lett. 2017, 8, 215-220.

24. Saghatelian, A.; Jessani, N.; Joseph, A.; Humphrey, M.; Cravatt, B. F. Proc. Natl. Acad. Sci. USA 2004, 101, 10000-5.

25. Salisbury, C. M.; Cravatt, B. F. Proc. Natl. Acad. Sci. USA 2007, 104, 1171-6.

26. Kennedy, D. C.; McKay, C. S.; Legault, M. C.; Danielson, D. C.; Blake, J. A.; Pegoraro, A. F.; Stolow, A.; Mester, Z.; Pezacki, J. P. J. Am. Chem. Soc. 2011, 133, 17993-8001.

27. Speers, A. E.; Adam, G. C.; Cravatt, B. F. J. Am. Chem. Soc. 2003, 125, 4686-7.

28. Valeur, E.; Bradley, M. Chem. Soc. Rev. 2009, 38, 606-31.

29. Thomas, P.; Smart, T. G. J. Pharmacol. Toxicol. Methods 2005, 51, 187-200.

30. Cheng, D.; Valente, S.; Castellano, S.; Sbardella, G.; Di Santo, R.; Costi, R.; Bedford, M. T.; Mai, A. J. Med. Chem. 2011, 54, 4928-32. 
31. Dillon, M. B.; Bachovchin, D. A.; Brown, S. J.; Finn, M. G.; Rosen, H.; Cravatt, B. F.; Mowen, K. A. ACS Chem. Biol. 2012, 7, 1198-204.

32. Wagner, E. J.; Carpenter, P. B. Nat. Rev. Mol. Cell Biol. 2012, 13, 115-126.

33. Li, J.; Duns, G.; Westers, H.; Sijmons, R.; van den Berg, A.; Kok, K. Oncotarget 2016, 7, 50719-50734.

34. Saredi, G.; Huang, H.; Hammond, C. M.; Alabert, C.; Bekker-Jensen, S.; Forne, I.;

Reverón-Gómez, N.; Foster, B. M.; Mlejnkova, L.; Bartke, T.; Cejka, P.; Mailand, N.; Imhof, A.; Patel, D. J.; Groth, A. Nature 2016, 534, 714-718.

35. Campos, E. I.; Smits, A. H.; Kang, Y. H.; Landry, S.; Escobar, T. M.; Nayak, S.;

Ueberheide, B. M.; Durocher, D.; Vermeulen, M.; Hurwitz, J.; Reinberg, D. Mol. Cell 2015, 60, 697-709.

36. Chen, C.; Nott, T. J.; Jin, J.; Pawson, T. Nat. Rev. Mol. Cell Biol. 2011, 12, 629-642.

37. Huang, Y.; Fang, J.; Bedford, M. T.; Zhang, Y.; Xu, R. M. Science 2006, 312, 748-51. 
Figure 1. A) Design and synthesis of BpyneSF.1a) 5-Hexynoic acid, HATU, trimethylamine, DMF, Argon, $80^{\circ} \mathrm{C}(13 \%)$; 1b) N-(tert-butoxycarbonyl)glycine, HATU, trimethylamine, DMF, Argon, $65^{\circ} \mathrm{C}(35 \%)$; 2a) (Boc) $)_{2}$-Sinefungin, HATU, Diisopropylamine, anhydrous DMF, Argon, $60^{\circ}$ C. 2b) Trifluoroacetic acid, RT (48\%). B) Structure of small molecules important in SAMdependent methyltransferases. C) structure of CARM1 inhibitor 1-Benzyl-3,5-bis-(3-bromo-4hydroxylbenzylidene)piperidin-4-one.

Figure 2. Schematic representation of ABPP. Extracted proteome is treated with inhibitor, followed by the addition of BpyneSF and click reaction with rhodamine-azide (Rh-Azide). Labelled proteome is separated by SDS-PAGE and differences in fluorescence banding is observed. Extracted proteome can also be treated initially with BpyneSF, followed by on-bead biotin/streptavidin $(\mathrm{B} / \mathrm{S})$ capture. Captured proteins are digested using trypsin and analyzed via mass spectrometry.

Figure 3. In vitro activity labeling of HEK293 proteome. A) Structure of BpyneSF activity probe; B) BpyneSF concentration-dependent labeling of HEK293 proteomes $(0.5 \mathrm{mg} / \mathrm{ml})$. Asterisks indicates concentration-dependent increases in band intensity. Arrow indicates location of SETD2.

Figure 4. In vitro activity labeling of HEK293 proteome. A) Optimization of BpyneSF incubation time for labeling HEK293 proteome with 10 $\mu \mathrm{M}$ of BpyneSF; B) Optimization of BpyneSF incubation with rhodamine azide for labeling HEK293 proteome with $10 \mu \mathrm{M}$ of BpyneSF; C) Competitive inhibition of BpyneSF labeling. HEK293 proteome was first treated with CARM1 inhibitor, 1-Benzyl-3,5-bis-(3-bromo-4-hydroxylbenzylidene)piperidin-4-one, for $30 \mathrm{~min}$ at RT, followed by incubation for 5 min with BpyneSF $(10 \mu \mathrm{M})$.

Figure 5. In vitro activity labeling of CARM1, PRMT1, and SETD2. $1 \mu \mathrm{g}$ of purified protein was incubated for 45 min with BpyneSF $(10 \mu \mathrm{M})$ and UV irradiated for 45 minutes, followed by click-attachment to rhodamine azide. CARM1 was visualized at $66 \mathrm{kDa}$, PRMT1 was visualized at $68 \mathrm{kDa}$, and SETD2 was visualized at $60 \mathrm{kDa}$. 
A

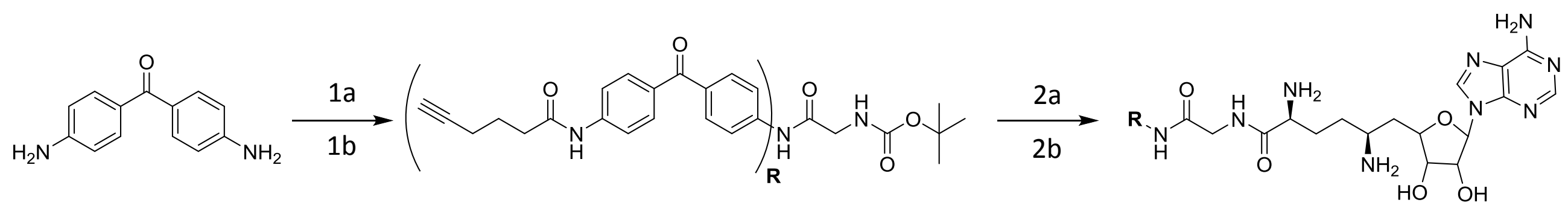

4,4'-diaminobenzophenone (Bp)

B

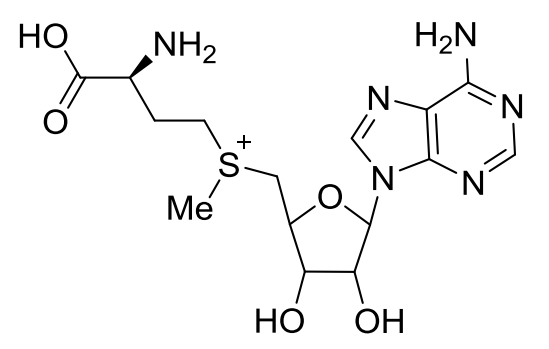

$S$-(5'-Adenosyl)-L-methionine (SAM)
Bpyne-gly-BOC

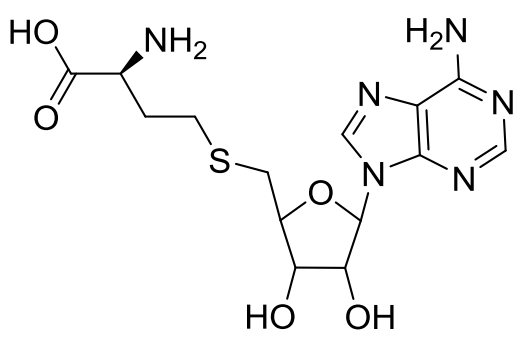

$S$-(5'-Adenosyl)-L-homocysteine (SAH)

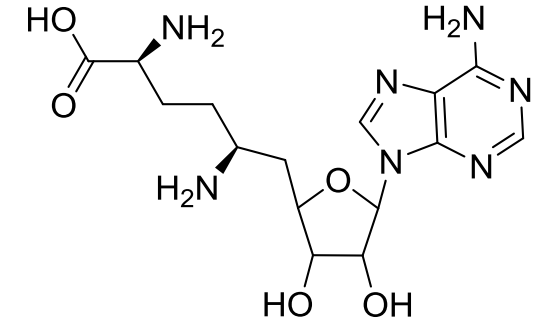

Sinefungin (SF)
BpyneSF

C

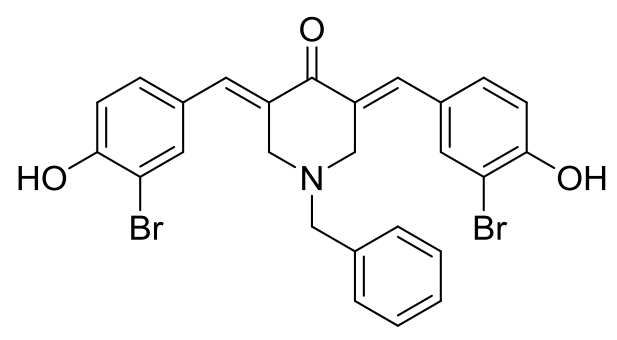

CARM1 inhibitor 


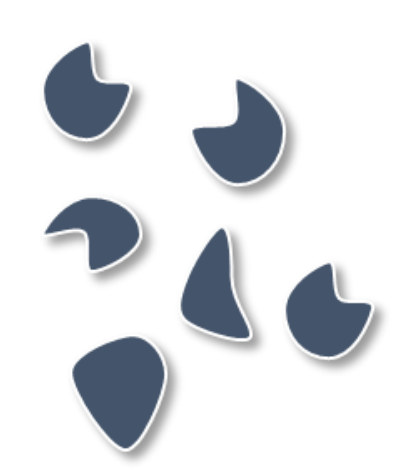

Extracted proteome

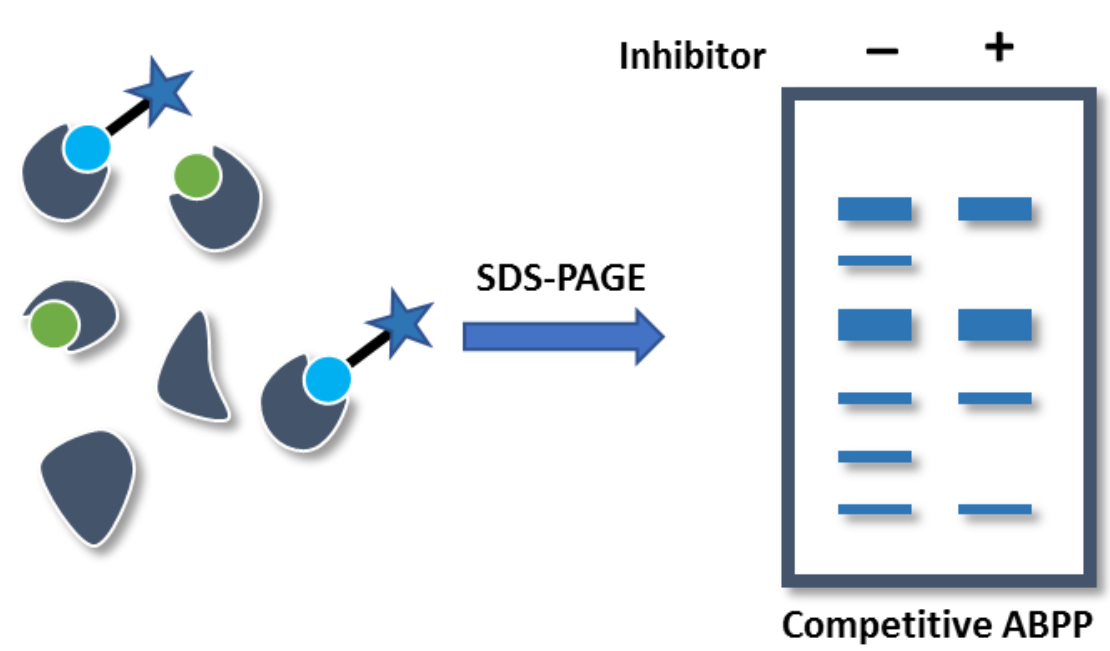

+ On-bead B/S capture

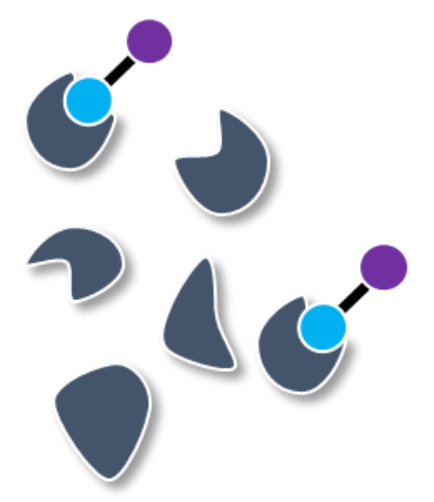

+ BpyneSF

+ Rh-Azide

$\rightarrow$

On-bead digest

MS analysis

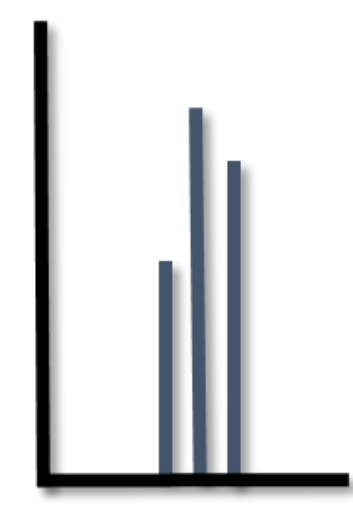<smiles>[14CH3]</smiles>
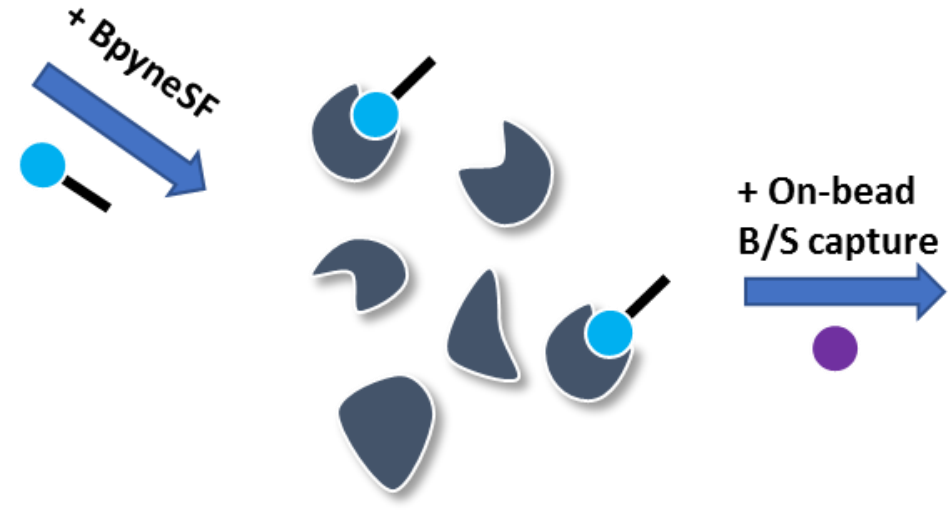

Target Identification 


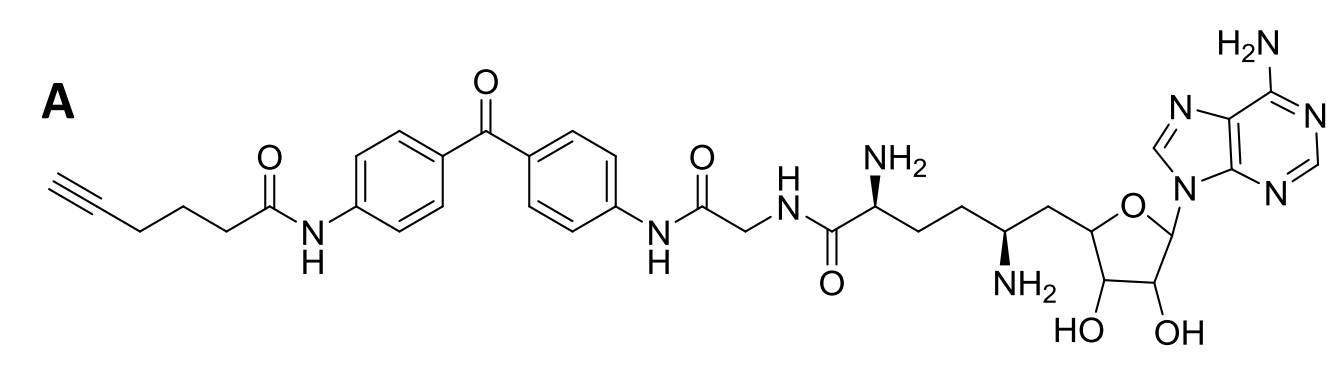

B

No hv

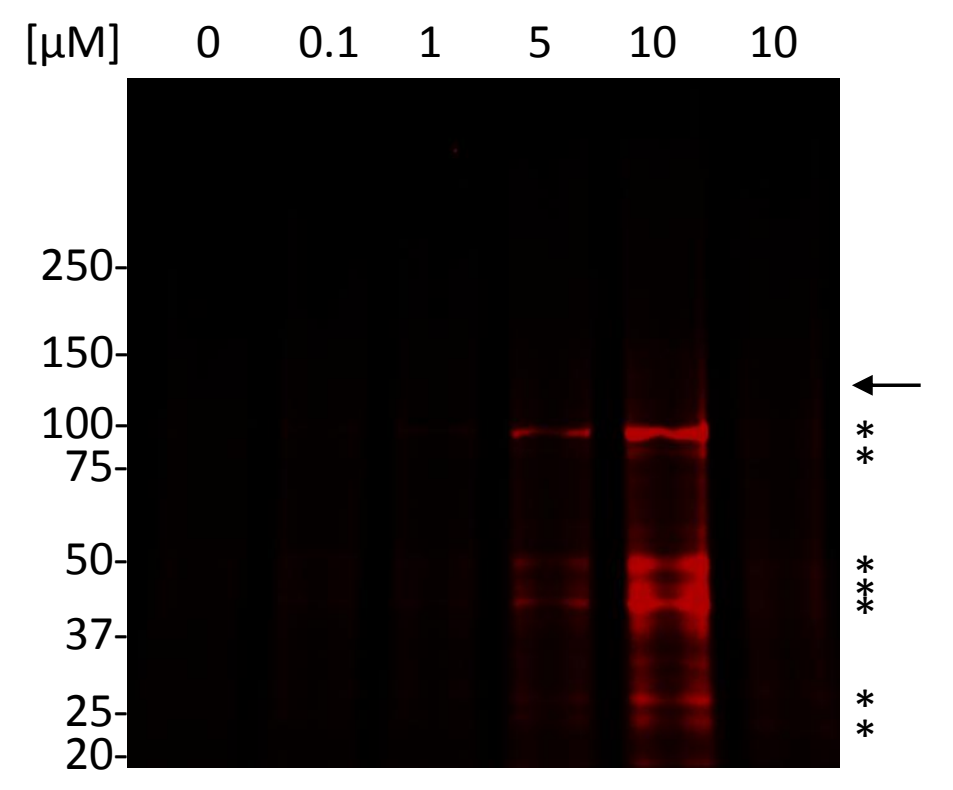

https://mc06.manuscriptcentral.com/cjc-pubs 
A

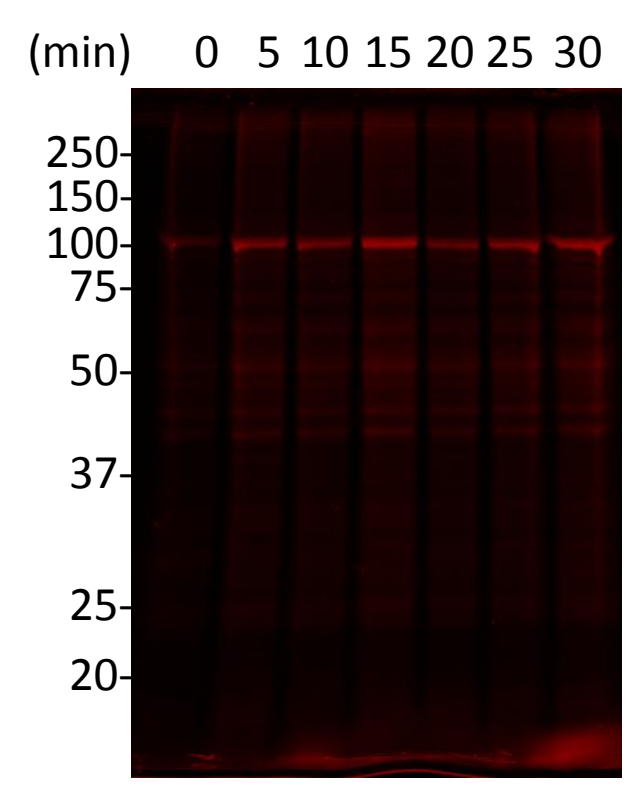

B

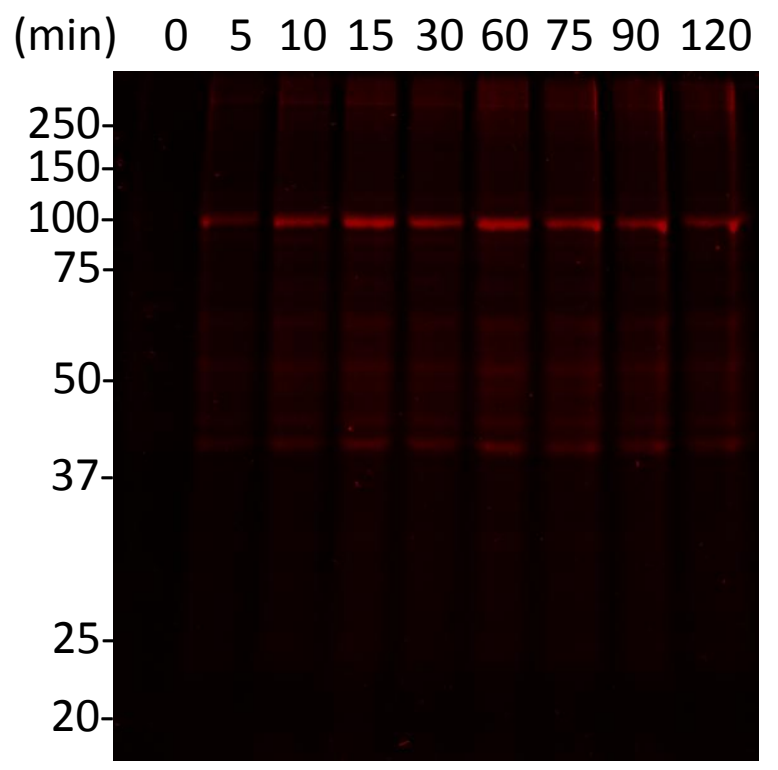

C

BpyneSF $[10 \mu \mathrm{M}]: \quad-\quad++++$ CARM1 inhibitor $[\mu \mathrm{M}]$ :

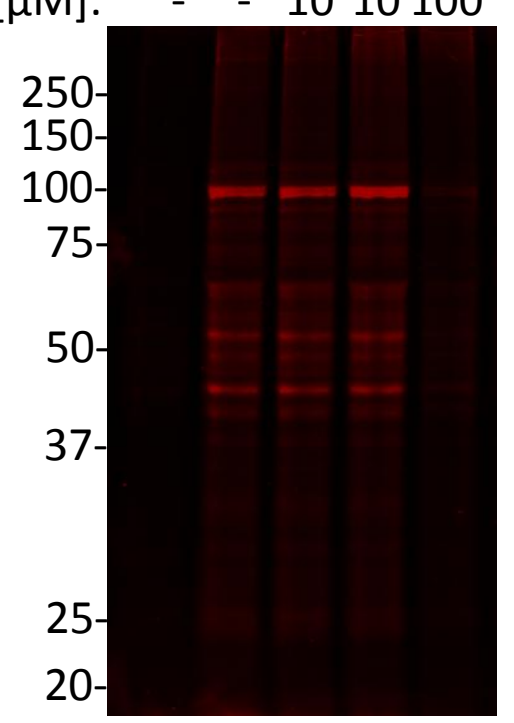




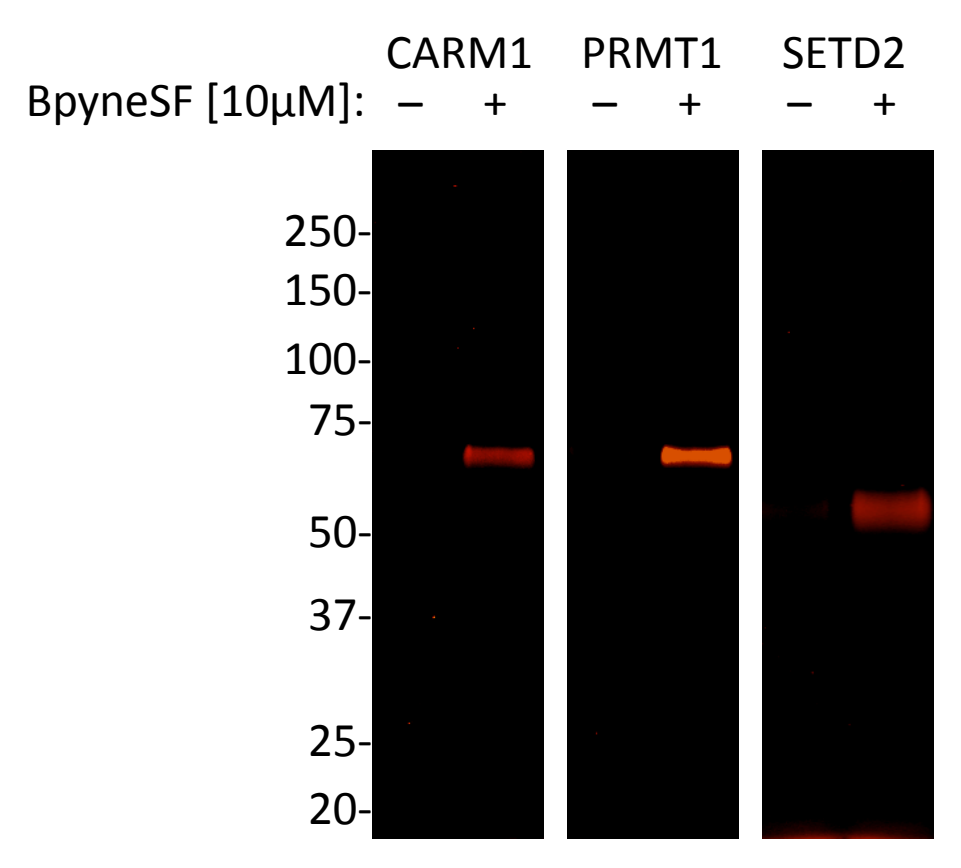

